\title{
Antimicrobial activities of the methanol extract and compounds from the twigs of Dorstenia mannii (Moraceae)
}

\author{
Armelle T Mbaveng ${ }^{1,2^{*}}$, Victor Kuete ${ }^{1,5^{*}}$, Bathelemy Ngameni ${ }^{3}$, Veronique P Beng ${ }^{2}$, Bonaventure T Ngadjui ${ }^{3,4}$,
} Jacobus J Marion Meyer ${ }^{5}$ and Namrita Lall ${ }^{5}$

\begin{abstract}
Background: Dorstenia mannii (Moraceae) is a medicinal herb used traditionally for the treatment of many diseases. In the present study, the methanol extract of $D$. mannii and nine of its isolated compounds, namely dorsmanin $A$ (1), B (2), C (3), D (4), E (6), F (7), G (8) dorsmanin I (9) and 6,8-diprenyleriodictyol (5), were tested for their antimicrobial activities against yeast, Mycobacteria and Gram-negative bacteria.

Methods: The microplate alamar blue assay (MABA) and the broth microdilution method were used to determine the minimal inhibitory concentration (MIC) and minimal microbicidal concentration (MMC) of the above extract and compounds on a panel of bacterial species.

Results: The results of the MIC determinations demonstrated that the methanol extract as well as compounds 3 and 8 were able to prevent the growth of all the fourteen studied microorganisms within the concentration range of 4 to $1024 \mu \mathrm{g} / \mathrm{ml}$. The lowest MIC value for the methanol extract $(64 \mu \mathrm{g} / \mathrm{ml})$ was obtained on Candida albicans. The lowest value for individual compounds $(4 \mathrm{\mu g} / \mathrm{ml}$ ) was recorded with compounds 3 on Pseudomonas aeruginosa PA01 and 7 on Eschericia coli ATCC strain. The MIC values recorded with compounds 3 on P. aeruginosa PA01, 6 on C. albicans, 7 on P. aeruginosa PA01 and K. pneumoniae ATCC strain and C. albicans,and 8 on P. aeruginosa PA01, PA124, P. stuartii, M. tuberculosis MTCS1 were lower than or equal to those of the reference drugs. MMC values not greater than $1024 \mathrm{\mu g} / \mathrm{ml}$ were recorded on all studied microorganisms with compounds 3 and 8 .

Conclusion: The overall results of the present investigation provided evidence that the crude extract of $D$. mannii as well as some of its compounds such compounds 3 and 8 could be a potential source of natural antimicrobial products.
\end{abstract}

\section{Background}

Many plant species of the genus Dorstenia (Moraceae) are used for medicinal purposes in Africa, Middle East, Central and South America. African Dorstenia species has yielded a variety of mono-, di-, and triprenylated and also mono- and digeranylated flavonoids with interesting pharmacological properties [1-4]. Dorstenia mannii Hook f. (Moraceae) is a perennial herb growing in the tropical rain forest of West Africa [5]. A decoction of

\footnotetext{
*Correspondence: armkuete@yahoo.fr; kuetevictor@yahoo.fr

'Department of Biochemistry, Faculty of Science, University of Dschang, P.O Box 67, Dschang, Cameroon

2Department of Biochemistry, Faculty of Science, University of Yaounde I, P. O. Box 812, Yaounde, Cameroon

Full list of author information is available at the end of the article
}

the leaves is used for the treatment of many diseases, but mainly for rheumatism and stomach disorders [6]. There are few pharmacological studies reported on $D$. mannii. However, prenylated flavonoids isolated from $D$. mannii such as 6,8-diprenyleriodictyol (5), dorsmanin C (3) and dorsmanin F (7) were found to be potent scavengers of the stable free radical 1,1-diphenyl-2-picrylhydrazyl [7]. Compounds 3, 5 and 7 also inhibited $\mathrm{Cu}^{2}$ ${ }^{+}$-mediated oxidation of human low density lipoprotein [7]. In our continuous search of bioactive compounds from the genus Dorstenia, the present work was designed to evaluate the antimicrobial potency of the methanol extract and compounds isolated from $D$. mannii.

\section{Ciomed Central}




\section{Methods}

\section{Plant material and extraction}

The twigs of Dorstenia mannii Hook. f. were collected at Nkoljobe mountain, Yaounde, Center region of Cameroon in March 2008. The plant was identified by Mr. Victor Nana of the National herbarium (Yaoundé, Cameroon) where a voucher specimen was deposited under the reference number $2135 / \mathrm{HNC}$.

The air dried and powdered twigs (1 kg) were extracted with methanol $(\mathrm{MeOH})$ for $48 \mathrm{~h}$ at room temperature. The extract was then concentrated under reduced pressure to give $185 \mathrm{~g}$ of a brown residue that constituted the crude extract (DMT).

\section{Chemicals for antimicrobial assay}

Chloramphenicol (Sigma-Aldrich, St. Quentin Fallavier, France) and Nystatin (Sigma-Aldrich) were used as reference antibiotics (RA) respectively against bacteria and Candida albicans. p-Iodonitrotetrazolium chloride (INT, Sigma-Aldrich) was used as microbial growth indicator $[8,9]$. Ciprofloxacin and isoniazid (INH) (Sigma) were used as reference antibiotics (RA) for M. smegmatis and $M$. tuberculosis respectively. The isolation and identification of compounds $\mathbf{1}$ to $\mathbf{9}$ from DMT were conducted as previously described [10-12]. The chemical structures of the isolated compounds are illustrated in Figure 1.

\section{Antimicrobial assays}

\section{Microbial strains and culture media}

The studied microorganisms included strains of Providencia stuartii, Pseudomonas aeruginosa, Klebsiella pneumoniae, Enterobacter aerogenes, Escherichia coli, Candida albicans four Mycobacteria namely M. smegmatis, drug-susceptible strain of M. tuberculosis H37Rv obtained from the American Type Culture Collection, and two clinical strains of $M$. tuberculosis MTCS1, MTCS2. M. smegmatis was cultured on Middlebrook 7 H11 agar and allowed to grow for 24 h. M. tuberculosis was plated on Löwenstein-Jensen medium and allowed to grow for $3-4$ weeks at $37^{\circ} \mathrm{C}$. Middlebrook $7 \mathrm{H} 9$ broth was used to determine the MIC and MMC values of the test samples on M. smegmatis and M. tuberculosis. Nutrient Agar and Sabouraud Glucose Agar were used for the activation of Gram-negative bacteria and fungi respectively [13]. The clinical strains used in this work are our Laboratory collection previously obtained from Yaoundé General Hospital (Cameroon), and from the Mediterranean University (Marseille, France).

\section{INT colorimetric assay for MIC and MMC determinations} The MIC determinations on M. smegmatis, fungi, and Gram-negative bacteria were conducted using rapid INT colorimetric assay according to previously described methods $[8,9]$ with some modifications. The test samples and RA were first of all dissolved in DMSO/MHB or DMSO/7 H9 broth. The final concentration of DMSO was lower than $2.5 \%$ and does not affect the microbial growth [14]. The solution obtained was then added to $7 \mathrm{H} 9$ broth (M. smegmatis) or MHB (other organisms), and serially diluted two fold (in a 96- wells microplate). $100 \mu \mathrm{l}$ of inoculum $1.5 \times 10^{6} \mathrm{CFU} / \mathrm{ml}$ prepared in appropriate broth was then added [15]. The plates were covered with a sterile plate sealer, then agitated to mix the contents of the wells using a plate shaker and incubated at $37^{\circ} \mathrm{C}$ for $18 \mathrm{~h}$. The assay was repeated thrice. Wells containing adequate broth, $100 \mu \mathrm{l}$ of inoculum and DMSO to a final concentration of $2.5 \%$ served as negative control. The MIC of samples was detected after $18 \mathrm{~h}$ incubation at $37^{\circ} \mathrm{C}$, following addition $(40 \mu \mathrm{l})$ of $0.2 \mathrm{mg} / \mathrm{ml} p$-iodonitrotetrazolium chloride (INT) and incubation at $37^{\circ} \mathrm{C}$ for 30 minutes. Viable bacteria reduced the yellow dye to a pink. MIC was defined as the sample concentration that prevented this change and exhibited complete inhibition of microbial growth. The MMC was determined by adding $50 \mu \mathrm{l}$ aliquots of the preparations, which did not show any growth after incubation during MIC assays, to $150 \mu \mathrm{l}$ of adequate broth. These preparations were incubated at $37^{\circ} \mathrm{C}$ for $48 \mathrm{~h}$. The MMC was regarded as the lowest concentration of extract, which did not produce a color change after addition of INT as mentioned above $[14,16]$.

\section{Microplate Alamar Blue assay against M. tuberculosis}

The activity of all samples against $M$. tuberculosis strains was tested using the MABA [17]. Briefly, each of the above $M$. tuberculosis strains was cultured at $37^{\circ} \mathrm{C}$ in Middlebrook 7 H9 broth supplemented with $0.2 \%$ glycerol and 10\% Oleic Acid-Albumin-Dextrose-Catalase (Sigma) until logarithmic growth was reached. About $6 \times 10^{6} \mathrm{CFU} / \mathrm{ml}$ inoculum of $M$. tuberculosis was then added to the two fold serially diluted samples. The final concentration of DMSO in all assays was $2.5 \%$ or less and this dilution also served as solvent control. The samples were assayed in triplicate. All tests were carried out in sterile flat-bottomed 96-well microplates. Each microplate was incubated for 5 days at $37^{\circ} \mathrm{C}$ in a $5 \%$ $\mathrm{CO}_{2}$ atmosphere in a sealed plastic $\mathrm{CO}_{2}$-permeable bag. After 5 days of incubation, $32 \mu$ l of a mixture of freshly prepared Alamar Blue solution and 20\% sterile Tween80 (Sigma) 1:1 v/v were added to one growth-control well. The microplates were incubated again at $37^{\circ} \mathrm{C}$ for $24 \mathrm{~h}$. If a color shift from blue to pink was observed in the growth-control sample, $32 \mu$ of alamar blue solution was added to each of the remaining wells, and the microplate was further incubated for $24 \mathrm{~h}$. A welldefined pink color was interpreted as positive bacterial 


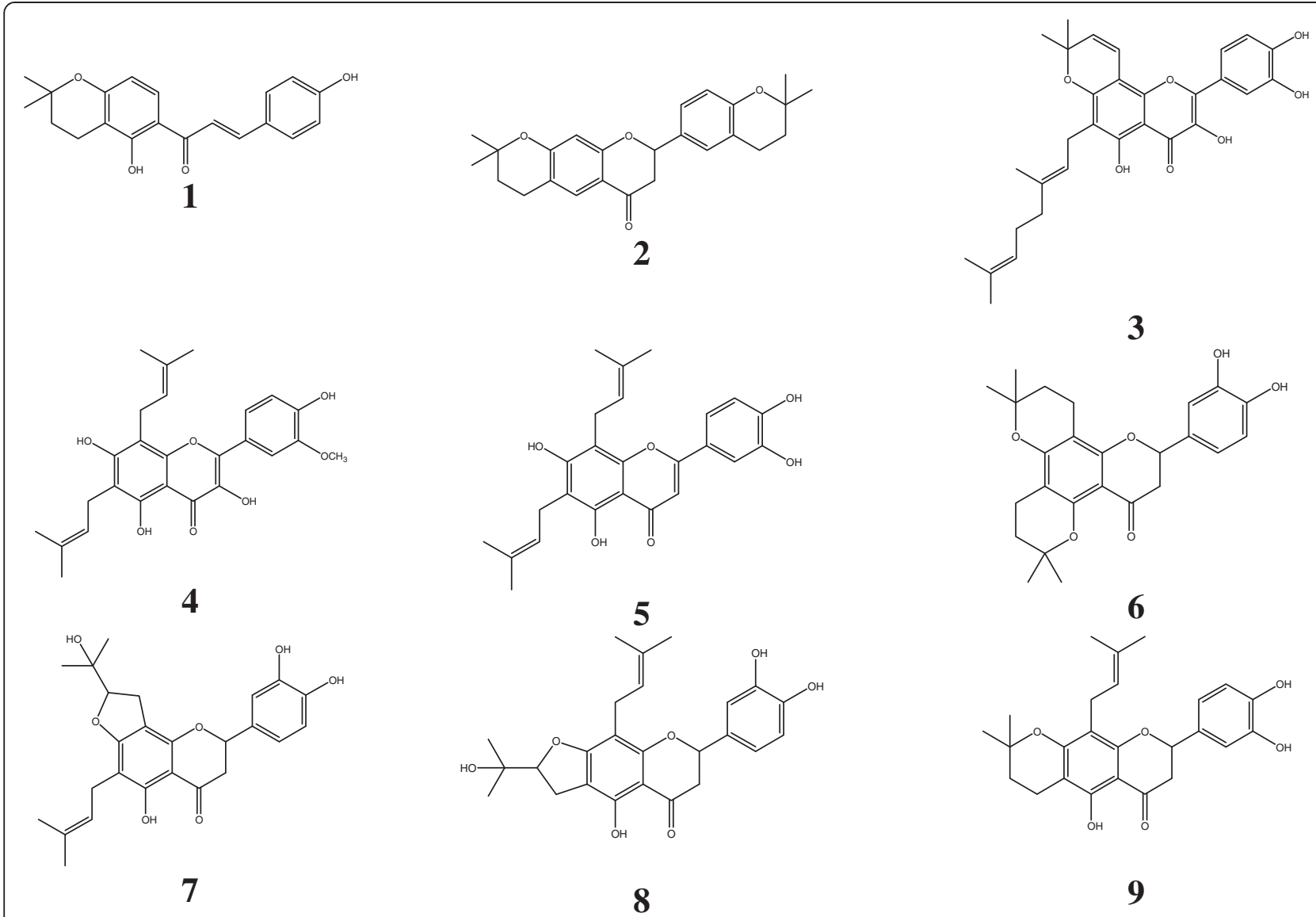

Figure 1 Chemical structures of the compounds isolated from the twigs of Dortenia mannii. Dorsmanins $A(\mathbf{1}), B(2), C(3), D(4), E(6), F(7), G$ (8), I (9) and 6,8 diprenyleriodictyol (5).

growth, whereas a blue color indicated an absence of growth. The MIC corresponded to the greatest dilution of sample extract in which the color shift from blue to pink was not observed.

Samples with recorded MIC values following MABA were assayed for their mycobactericidal effect [17]. Briefly, $5 \mu \mathrm{l}$ of the undeveloped mycobacterial suspensions were transferred from the former to a new microplate that contained $195 \mu \mathrm{l}$ of fresh culture medium per well. Three wells were inoculated with $100 \mu \mathrm{l}$ of fresh inoculum as for MABA and three more wells were incubated with $200 \mu \mathrm{l}$ of culture medium only, as negative controls. The microplates were incubated and developed with alamar blue as for MABA. The MMC corresponded to the minimum sample concentration that did not cause a color shift in cultures that were re-incubated in fresh medium.

\section{Results and discussion}

The tested compounds were isolated from DMT and identified as previously described as dorsmanin A (1), B (2), C (3), D (4) and 6,8-diprenyleriodictyol (5) [10], dorsmanin E (6), F (7), G (8) [11] and dorsmanin I (9) [12]. These compounds together with the crude methanol extract were tested for their antimicrobial activities against bacteria and yeasts and the results are reported in Tables 1 and 2.

The results of the MIC determinations (Table 1) demonstrated that the methanol extract as well as compounds 3 and $\mathbf{8}$ were able to prevent the growth of all the fourteen studied microorganisms, including mycobacteria, yeast and Gram-negative bacteria, within the concentration range of 4 to $1024 \mu \mathrm{g} / \mathrm{ml}$. Other compounds showed selective activities, their inhibitory effects being noted on $12 / 14$ (85.7\%) studied pathogens for compound 7, 7/14 (50\%) for compound 6, 6/14 (42.9\%) for compounds $9,5 / 14$ (35.7\%) for compounds 2 and 5, 3/14 (21.4\%) for compounds 1 and 4 . The lowest MIC value for the methanol extract $(64 \mu \mathrm{g} / \mathrm{ml})$ was obtained on C. albicans. The lowest value for individual compounds $(4 \mu \mathrm{g} / \mathrm{ml})$ was recorded with compounds 3 on P. aeruginosa PA01 and 7 on E. coli ATCC strain. The corresponding values for the RA ranged from 0.5 to $64 \mu \mathrm{g} / \mathrm{ml}, \quad$. aeruginosa PA01 and $M$. tubercolosis 
Table 1 Minimal inhibitory concentrations (MIC in $\mu \mathrm{g} / \mathrm{ml}$ ) of the studied samples and reference antibiotics against the tested microorganisms

\begin{tabular}{|c|c|c|c|c|c|c|c|c|c|c|c|c|c|c|}
\hline \multicolumn{3}{|c|}{ Tested samples* } & \multicolumn{11}{|c|}{ Microorganisms, strains and MIC $(\mu \mathrm{g} / \mathrm{ml})$} & \\
\hline & \multicolumn{2}{|l|}{ E. coli } & \multicolumn{4}{|c|}{ P. aeruginosa K. pneumoniae } & \multicolumn{2}{|c|}{ E.aerogenes } & \multicolumn{6}{|c|}{ P. stuartiiC. albicans M. smegmatisM. tuberculosis } \\
\hline \multirow[b]{2}{*}{ DMT } & \multicolumn{3}{|c|}{ ATCC10536AG100PA01 } & \multirow{2}{*}{\begin{tabular}{|l|} 
PA124 \\
1024
\end{tabular}} & \multicolumn{2}{|c|}{ ATCC11296KP5 } & 5 ATCC13048 & \multicolumn{2}{|c|}{ 18CM64NAE16 } & \multicolumn{5}{|c|}{ ATCC 9002 ATCC 700084 ATCC 27294MTCS1MTCS2 } \\
\hline & 256 & 512 & 512 & & 128 & 512 & 128 & 512 & 128 & 64 & 128 & 128 & 1024 & 512 \\
\hline 1 & 512 & - & - & - & - & - & 128 & - & 128 & - & - & NT & NT & NT \\
\hline 2 & 128 & 128 & - & - & - & - & - & - & 1024 & - & 512 & 512 & - & - \\
\hline 3 & 64 & 64 & 4 & 64 & 128 & 64 & 32 & 64 & 16 & 64 & 64 & 32 & 128 & 32 \\
\hline 4 & - & - & 128 & - & 512 & - & - & - & 1024 & - & - & NT & NT & NT \\
\hline 5 & 512 & - & - & - & 1024 & - & 32 & - & 128 & 32 & - & NT & NT & NT \\
\hline 6 & 512 & 128 & 512 & - & 128 & - & 16 & - & 256 & 8 & - & NT & NT & NT \\
\hline 7 & 4 & 256 & 32 & - & 8 & 64 & 16 & - & 64 & 16 & 128 & 128 & 256 & 128 \\
\hline 8 & 16 & 128 & 8 & 32 & 128 & 32 & 64 & 32 & 32 & 128 & 64 & 64 & 64 & 64 \\
\hline 9 & - & - & - & - & - & - & 256 & - & 256 & 32 & 128 & 256 & - & 512 \\
\hline$R A^{b}$ & 2 & 8 & 64 & 32 & 8 & 4 & 8 & 4 & 32 & 16 & 0.5 & 0.5 & 64 & 2 \\
\hline
\end{tabular}

${ }^{a}$ Tested samples [DMT: methanol extract from the twigs of Dorstenia mannii; dorsmanins $\mathrm{A}(\mathbf{1}), \mathrm{B}(\mathbf{2}), \mathrm{C}(\mathbf{3}), \mathrm{D}(\mathbf{4}) \mathrm{E}(\mathbf{6}), \mathrm{F}(\mathbf{7}), \mathrm{G}(\mathbf{8}), \mathrm{I}(\mathbf{9})$ and 6,8 diprenyleriodictyol (5); ${ }^{b} \mathrm{RA}$ : reference antibiotics were chloramphenicol for bacteria, nystatin for C. albicans, ciprofloxacin for M. smegmatis, isoniazid for M.tuberculosis; (-): MIC $>1024 \mu \mathrm{g} / \mathrm{ml}$

MTCS1 being the least sensitive. Results of MMC determinations (Table 2) also showed good activities for some of the tested samples such as compounds $\mathbf{3}$ and $\mathbf{8}$. MMC values not greater than $1024 \mu \mathrm{g} / \mathrm{ml}$ were recorded on all studied microorganisms with compounds 3 and $\mathbf{8}$, on 12/14 (85.7\%) studied organisms for compound 7, 9/14 (64.3\%) for the crude extract, $4 / 14$
(28.6\%) for compound $\mathbf{9}, 3 / 14$ (21.4\%) for compounds 5 and 6, 2/14 (14.3\%) for compounds 1 and $2,1 / 14$ (7.1\%) for compound 4.

The compounds isolated from D. mannii and tested herein were all flavonoids. This class of compounds is very common in the genus Dorstenia [10-12] and their antimicrobial activities were also reported [2-4]. In the

Table 2 Minimal microbicidal concentrations (MMC in $\mu \mathrm{g} / \mathrm{ml}$ ) of the studied samples and reference antibiotics against the tested microorganisms

\begin{tabular}{|c|c|c|c|c|c|c|c|c|c|c|c|c|c|c|}
\hline \multicolumn{6}{|c|}{ Tested samples* } & \multicolumn{9}{|c|}{ Microorganisms, strains and MMC $(\mu \mathrm{g} / \mathrm{ml})$} \\
\hline & \multicolumn{2}{|l|}{ E. coli } & \multicolumn{4}{|c|}{ P. aeruginosaK. pneumoniae } & \multicolumn{2}{|c|}{ E.aerogenes } & \multicolumn{6}{|c|}{ P. stuartiiC. albicans M. smegmatisM. tuberculosis } \\
\hline & \multicolumn{3}{|c|}{ ATCC10536AG100PA01 } & \multicolumn{6}{|c|}{ PA124 ATCC11296KP55ATCC13048CM64 NAE16 } & \multicolumn{5}{|c|}{ ATCC 9002 ATCC 700084 ATCC 27294MTCS1MTCS2 } \\
\hline \multirow{2}{*}{$\begin{array}{l}\text { DMT } \\
\mathbf{1}\end{array}$} & \multirow{2}{*}{$\begin{array}{l}512 \\
>1024\end{array}$} & \multicolumn{2}{|c|}{$>10241024$} & \multicolumn{2}{|c|}{$>1024512$} & \multicolumn{2}{|c|}{1024512} & \multicolumn{2}{|c|}{$>1024256$} & \multirow{2}{*}{$\begin{array}{l}128 \\
N D\end{array}$} & \multirow{2}{*}{$\begin{array}{l}256 \\
N D\end{array}$} & \multirow{2}{*}{$\begin{array}{l}256 \\
\text { NT }\end{array}$} & \multicolumn{2}{|c|}{$>1024>1024$} \\
\hline & & ND & ND & ND & ND & ND & 1024 & ND & 1024 & & & & NT & NT \\
\hline 2 & 1024 & 1024 & ND & ND & ND & ND & ND & ND & $>1024$ & ND & 512 & $>1024$ & ND & ND \\
\hline 3 & 128 & 128 & 8 & 128 & 256 & 128 & 64 & 128 & 64 & 128 & 128 & 64 & 256 & 64 \\
\hline 4 & ND & ND & 1024 & ND & $>1024$ & ND & ND & ND & $>1024$ & ND & ND & NT & NT & NT \\
\hline 5 & $>1024$ & ND & ND & ND & $>1024$ & ND & 128 & ND & 1024 & 64 & ND & NT & NT & NT \\
\hline 6 & $>1024$ & \multicolumn{3}{|c|}{$>1024>1024 \mathrm{ND}$} & 256 & ND & 64 & ND & $>1024$ & 16 & ND & NT & NT & NT \\
\hline 7 & 8 & 512 & 64 & ND & 16 & 256 & 32 & ND & 256 & 32 & 256 & 256 & 1024 & 512 \\
\hline 8 & 32 & 512 & 16 & 64 & 256 & 128 & 128 & 128 & 64 & 256 & 128 & 128 & 128 & 128 \\
\hline 9 & ND & $N D$ & ND & ND & ND & ND & 1024 & ND & $>1024$ & 64 & 1024 & 512 & ND & $>1024$ \\
\hline $\mathrm{RA}^{\mathrm{b}}$ & 4 & 32 & 128 & 128 & 32 & 16 & 16 & 16 & 128 & 32 & 1 & 1 & 128 & 4 \\
\hline
\end{tabular}

${ }^{\mathrm{a}}$ Tested samples [DMT: methanol extract from the twigs of Dorstenia mannii; dorsmanins $\mathrm{A}(\mathbf{1}), \mathrm{B}(\mathbf{2}), \mathrm{C}(\mathbf{3}), \mathrm{D}(\mathbf{4}) \mathrm{E}(\mathbf{6}), \mathrm{F}(\mathbf{7}), \mathrm{G}(\mathbf{8}), \mathrm{I}(\mathbf{9})$ and 6,8 diprenyleriodictyol (5); ${ }^{\mathrm{b}} \mathrm{RA}$ : reference antibiotics were chloramphenicol for bacteria, nystatin for C. albicans, ciprofloxacin for M. smegmatis, isoniazid for M.tuberculosis; (-):

MIC $>1024 \mu \mathrm{g} / \mathrm{ml}$; (ND): not determined as MIC was $>1024 \mu \mathrm{g} / \mathrm{ml}$ 
present work, broad spectrum of antimicrobial activities was recorded with the crude extract and compounds from $D$. mannii. Phytochemicals are routinely classified as antimicrobials on the basis of susceptibility tests that produce MIC in the range of 100 to $1000 \mu \mathrm{g} / \mathrm{ml}$ [18]. Activity is considered to be significant if MIC values are below $100 \mu \mathrm{g} / \mathrm{ml}$ for crude extract and moderate when the MIC values vary from 100 to $625 \mu \mathrm{g} / \mathrm{ml}[19,20]$. Therefore, the activity recorded with the crude extract on $C$. albicans can be considered as important. Also, compounds with significant activities $(\mathrm{MIC}<10 \mu \mathrm{g} / \mathrm{ml})$ on at least one of the studied organisms include $3,6,7$ and 8. The MIC values recorded with compounds 3 on $P$. aeruginosa PA01, 6 on $C$. albicans, 7 on $P$. aeruginosa PA01 and $K$. pneumoniae ATCC strain, and C. albicans, 8 on $P$. aeruginosa PA01, PA124, P. stuartii, M. tuberculosis MTCS1 were lower than or equal to those of the reference drugs, highlighting their interesting activities. This observation is in consistence with previous work on flavonoids isolated from the genus Dorstenia. In fact, isobavachalcone, 4-hydroxylolonchocarpin, kanzonol C, stipulin, and many other flavonoids isolated from this genus were reported for their good antimicrobial potencies, with MIC values below $10 \mu \mathrm{g} / \mathrm{ml}$ on several tested microorganisms [2-4,21]. A Keen look at the MMC values indicates that most of them are not more than fourfold their corresponding MICs. This proves that the killing effects of many tested samples could be expected on the sensitive strains [22]. The continuous emergence of multidrug-resistant (MDR) bacteria drastically reduces the efficacy of our antibiotic armory and, consequently, increases the frequency of therapeutic failure [23]. MDR Enterobacteriaceae, including K. pneumoniae, $E$. aerogenes and E. coli have also been classified as antimicrobial-resistant organisms of concern in healthcare facilities [24]. Besides, K. pneumoniae KP55 tested herein was reported to be resistant to most of the commonly used antibiotics, showing high levels of resistance to ampicillin, ceftazidime, and aztreonam with MIC values up to $512 \mu \mathrm{g} / \mathrm{ml}$ [25]. In addition Pseudomonas aeruginosa has emerged as one of the most problematic Gram-negative pathogens, with the alarmingly high antibiotics resistance rates [26]. The good activities of compounds $\mathbf{3}$ and $\mathbf{8}$ on most of the tested strains belonging to MDR phenotypes such as E. coli AG100, P. aeruginosa PA124, E. aerogenes CM64, K. pneumoniae KP55 as observed herein reinforce the hypothesis that these compounds are natural products with interesting antimicrobial potencies.

Tuberculosis (TB) is widely expanded in poor countries with the highest incidence (more than $80 \%$ of cases) occurring in Asia and Africa [27]. Annual incidence of TB (over 600 cases per 100 000) has been reported in many sub-Saharan African countries [28]. In this work, only compounds with inhibitory activity on M. smegmatis were tested on $M$. tuberculosis. However, it has been demonstrated that the sensitivity of $M$. tuberculosis is closer to that of M. smegmatis, a non pathogenic microorganism [29]. Therefore, this microorganism can be used for a preliminary study to select samples with potential activity against $M$. tuberculosis [29]. Hence, the results obtained herein are in accordance with such recommendation.

To the best of our knowledge, the antimicrobial activity of $D$. mannii as well as that of the isolated compounds is being reported for the first time. However 6,8diprenyleridictyol (5) an,dorsmanin F (7) were reported for their antitrichomonal activities [30].

\section{Conclusion}

The data reported herein are very important, taking into account the medical importance of the studied microorganisms. Hence, the overall results of the present investigation provide evidence that the crude extract of $D$. mannii as well as some of its compounds such as compounds $\mathbf{3}$ and $\mathbf{8}$ could be considered as interesting natural antimicrobial products.

\section{Competing interests \\ The authors declare that they have no competing interests.}

\section{Acknowledgements}

Authors are thankful to the Cameroon National Herbarium (Yaounde) for the plant identification. Authors are also grateful to the International Foundation for Science (IFS-Grant F/4579-2 to VK). Authors are also thankful to UMR-MD1 (Mediterranean University, Marseille, France) for providing some clinical bacteria.

\section{Author details}

${ }^{1}$ Department of Biochemistry, Faculty of Science, University of Dschang, P.O. Box 67, Dschang, Cameroon. ${ }^{2}$ Department of Biochemistry, Faculty of Science, University of Yaounde I, P.O. Box 812, Yaounde, Cameroon. ${ }^{3}$ Department of Pharmacy and Traditional Pharmacopoeia, Faculty of Medicine and Biomedical Science, University of Yaoundé I, Yaounde, Cameroon. ${ }^{4}$ Department of Organic Chemistry, Faculty of Science, University of Yaoundé I, Yaounde, Cameroon. ${ }^{5}$ Department of Plant Science, Faculty of Agricultural and Biological Science, Pretoria 0002, South Africa.

\section{Authors' contributions}

ATM, VK and BN carried out the study; ATM and VK wrote the manuscript; VK, BTN, VPB, JJMM and NL supervised the work. All authors read and approved the final manuscript.

Received: 29 March 2012 Accepted: 29 June 2012

Published: 29 June 2012

\section{References}

1. Abegaz BM, Ngadjui BT, Dongo E, Bezabih M-T: Chemistry of the genus Dorstenia. Curr Org Chem 2000, 2000(4):107-109.

2. Kuete V, Simo IK, Ngameni B, Bigoga JD, Watchueng J, Kapguep RN, Etoa FX, Tchaleu BN, Beng VP: Antimicrobial activity of the methanolic extract, fractions and four flavonoids from the twigs of Dorstenia angusticornis Engl. (Moraceae). J Ethnopharmacol 2007, 112:271-277.

3. Mbaveng AT, Ngameni B, Kuete V, Konga Simo I, Ambassa T, Roy R, Bezabih M, Etoa FX, Ngadjui BT, Abegaz BM, Meyer JJM, Lall N, Penlap BV: Antimicrobial activity of the crude extracts and five flavonoids from the twigs of Dorstenia barteri (Moraceae). J Ethnopharmacol 2008, 116:483489. 
4. Ngameni B, Kuete V, Konga Simo I, Mbaveng AT, Awoussong PK, Patnam R, Roy R, Ngadjui BT: Antibacterial and antifungal activities of the crude extract and compounds from Dorstenia turbinata (Moraceae). S Afr J Bot 2009, 75:256-261.

5. Hutchinson J, Dalziel JM: In Flora of West Tropical Africa, 2nd ed. Edited by Keay RWJ.: ; 1954.

6. Bouquet A: Feticheurs et Medecines Traditionnelles du Congo Brazaville. Paris: ORSTOM; 1969.

7. Dufall KG, Ngadjui BT, Simeon KF, Abegaz BM, Croft KD: Antioxidant activity of prenylated flavonoids from the West African medicinal plant Dorstenia mannii. J Ethnopharmaco. 2003, 87:67-72.

8. Eloff JN: A sensitive and quick microplate method to determine the minimal inhibitory concentration of plant extracts for bacteria. Planta Med 1998, 64:711-713.

9. Mativandlela SPN, Lall N, Meyer JJM: Antibacterial, antifungal and antitubercular activity of (the roots of) Pelargonium reniforme (CURT) and Pelargonium sidoides (DC) (Geraniaceae) root. S Afr J Bot 2006, 72:232-237.

10. Ngadjui BT, Abegaz BM, Dongo E, Tanboue H, Fogue K: Geranylated and Prenylated flavonoids from the twigs of Dorstenia mannii. Phytochemistry 1998, 48:349-354.

11. Ngadjui BT, Dongo E, Tanboue H, Fogue K, Abegaz BM: Prenylated flavanones from the twigs of Dorstenia mannii. Phytochemistry 1998, 50:1401-1406.

12. Ngadjui BT, Kouam SF, Dongo E, Kapche GWF, Abegaz BM: Prenylated flavanoids from the aerial parts of Dorstenia mannii. Phytochemistry 2000, 55:915-919.

13. Kuete V, Kamga J, Sandjo LP, Ngameni B, Poumale HM, Ambassa P, Ngadjui BT: Antimicrobial activities of the methanol extract, fractions and compounds from Ficus polita Vahl. (Moraceae). BMC Complement Altern Med 2011, 11:6.

14. Kuete V, Ngameni B, Fotso Simo CC, Kengap Tankeu R, Tchaleu Ngadjui B, Meyer JJM, Lall N, Kuiate JR: Antimicrobial activity of the crude extracts and compounds from Ficus chlamydocarpa and Ficus cordata (Moraceae). J Ethnopharmacol 2008, 120:17-24.

15. Tereschuk ML, Riera MVQ, Castro GR, Abdala LR: Antimicrobial activity of flavonoid from leaves of Tagetes minuta. J Ethnopharmacol 1997, 56:227232.

16. Zgoda JR, Porter JR: A convenient microdilution method screening natural products against bacteria and fungi. Pharmaceut Biol 2001, 39:221-225

17. Jimenez-Arellanes A, Meckes M, Ramirez R, Torres J, Luna-Herrera J: Activity against multidrug-resistant Mycobacterium tuberculosis in Mexican plants used to treat respiratory diseases. Phytother Res 2003, 17:903-908.

18. Simões M, Bennett RN, Rosa EA: Understanding antimicrobial activities of phytochemicals against multidrug resistant bacteria and biofilms. Nat Prod Rep 2009, 26:746-757.

19. Kuete V: Potential of Cameroonian plants and derived products against microbial infections: a review. Planta Med 2010, 76:1479-1491.

20. Kuete V, Efferth T: Cameroonian medicinal plants: pharmacology and derived natural products. Front Pharmacol 2010, 1:123.

21. Kuete V, Ngameni B, Mbaveng AT, Ngadjui B, Marion Meyer JJ, Lall N: Evaluation of flavonoids from Dorstenia barteri for their antimycobacterial, antigonorrheal and anti-reverse transcriptase activities. Acta Trop 2010, 116:100-104.

22. Mims CA, Playfair JHL, Roitt IM, Wakelin D, Williams R: In Antimicrobials and chemotherapy. Edited by Mims CA, et al.; 1993:1-34. Med Microbiol Rev 35.

23. Rice LB: Unmet medical needs in antibacterial therapy. Biochem Pharmacol 2006, 71:991-995.

24. Nicolle LE: Infection control programmes to contain antimicrobial resistance. Geneva: World Health Organization; 2001. WHO/CDS/CSR/DRS/2001.7. http://whqlibdoc.who.int/hq/2001/WHO CDS CSR DRS 2001.7.pdf [accessed January 2009].

25. Chevalier J, Pagès J-M, Eyraud A, Malléa M: Membrane permeability modifications are involved in antibiotic resistance in Klebsiella pneumoniae. Biochem Biophys Res Commun 2000, 274:496-499.

26. Savafi L, Duran N, Savafi N, Onlen Y, Ocak S: The prevalence and resistance patterns of Pseudomonas aeruginosa in intensive care units in a university hospital. Turk J Med Sci 2005, 35:317-322.

27. Zager EM, McNerney R: Multidrug-resistant tuberculosis. BMC Infect Dis 2008, 8:10.
28. Corbett EL, Marston B, Churchyard GJ, De Cock KM: Tuberculosis in subSaharan Africa: opportunities, challenges, and change in the era of antiretroviral treatment. Lancet 2006, 367:926-927.

29. Newton SM, Lau C, Gurcha SS, Besra GS, Wright CW: The evaluation of forty-three plant species for in vitro antimycobacterial activities; isolation of active constituents from Psoralea corylifolia and Sanguinaria Canadensis. J Ethnopharmacol 2002, 79:57-67.

30. Omisore NOA, Adewunmi CO, Iwalewa EO, Ngadjui BT, Adenowo TK, Abegaz BM, Ojewole JA, Watchueng J: Antitrichomonal and antioxidant activities of Dorstenia barteri and Dorstenia convexa. Braz J Med Biol Res 2005, 38:1087-1094.

doi:10.1186/1472-6882-12-83

Cite this article as: Mbaveng et al:: Antimicrobial activities of the methanol extract and compounds from the twigs of Dorstenia mannii (Moraceae). BMC Complementary and Alternative Medicine 2012 12:83.

\section{Submit your next manuscript to BioMed Central and take full advantage of:}

- Convenient online submission

- Thorough peer review

- No space constraints or color figure charges

- Immediate publication on acceptance

- Inclusion in PubMed, CAS, Scopus and Google Scholar

- Research which is freely available for redistribution

Submit your manuscript at www.biomedcentral.com/submit
C) Biomed Central 